\title{
Epidemiology and outcomes of Endophthalmitis in chronic dialysis patients: a 13-year experience in a tertiary referral center in Taiwan
}

George Kuo ${ }^{1}$, Yueh-An Lu', Wei-Chiao Sun ${ }^{1}$, Chao-Yu Chen ${ }^{1}$, Huang-Kai Kao ${ }^{2}$, YuJr Lin ${ }^{3}$, Chia-Hui Lee ${ }^{4}$, Cheng-Chieh Hung ${ }^{1}$, Ya-Chung Tian ${ }^{1}$ and Hsiang-Hao Hsu ${ }^{1 *}$

\begin{abstract}
Background: Endophthalmitis is a severe eye infection leading to disabling outcome. Because there were only a few case report illustrating endophthalmitis in chronic dialysis patient, we would like to investigate the epidemiology and clinical features of endophthalmitis in chronic dialysis patient in a tertiary referral center.

Methods: We searched the health information system in the study hospital with ICD9 encoding endophthalmitis during Jan. 2002 to Dec. 2015. A total of 32 episodes of endophthalmitis occurred in chronic dialysis patients. We performed an 1:2 case-control match on propensity score. The demographic features, clinical manifestation, infection focus and visual outcome were recorded.

Results: Of the total of 32 patients, 25 were classified as endogenous endophthalmitis and another seven were exogenous. Most patients presented with ophthalmalgia $(n=32,100 \%)$ and periocular swelling $(n=31,96.8 \%)$, whereas half of the patients suffered blurred vision $(n=16,50 \%)$. Staphylococcus aureus, Klebsiella pneumoniae, and Pseudomonas aeruginosa were the most frequent causative pathogens. Dialysis vascular infection was also a possible unique focus for bacteremia. The visual acuity of the endogenous groups were less likely to improve in the chronic dialysis patients compared with control group.

Conclusion: This is the first and the largest case series focusing on endophthalmitis in chronic dialysis patients. Our study showed different pathogen spectrum, an unique bacterial origin and worse visual outcome in these group of patients. Prompt referral to ophthalmologists when the patients present with suspicious symptoms (blurred vision, ophthalmalgia and periocular swelling) is crucial.
\end{abstract}

Keywords: Blurred vision, Chronic dialysis, Endophthalmitis, Outcome, Ophthalmalgia

\section{Background}

Endophthalmitis is a serious ocular infection that frequently leads to blindness, and it can be further divided into endogenous and exogenous, based on the presence of ocular trauma or surgery prior to the onset of eye infection $[1,2]$.

\footnotetext{
* Correspondence: hsianghao@gmail.com

'Department of Nephrology, Kidney Research Center, Linkou Chang Gung Memorial Hospital, Chang Gung University, College of Medicine, No.5 Fu-Shin Street, Kwei-shan, Taoyuan 333, Taiwan

Full list of author information is available at the end of the article
}

Endogenous endophthalmitis usually presents with blurred vision and ocular pain, and only less than half of patients have systemic infectious signs including fever [3]. Retrospective studies demonstrated significant risk factors of endogenous endophthalmitis including diabetes, intravenous drug user, immunosuppressive therapy, active malignancies, and cardiac disease [3-8]. Exogenous endophthalmitis, especially those occur after cataract surgery, is widely described. The risk factors include diabetes, male gender, old age and lack of prophylactic perioperative antibiotics [9-11]. 
Despite extensive literatures in the general population, there are few studies and reports featuring this serious infection in chronic dialysis patients, of which the immunity is impaired and bloodstream infections are common [12-14]. We here described the largest series of endophthalmitis among chronic dialysis patients in a tertiary referral medical center in Northern Taiwan.

\section{Methods}

The study was carried on at Linkou Chang-Gung Memorial Hospital (CGMH), a tertiary referral centre with about 3700 beds and an average of 107,00 episodes in-patient service annually. This study protocol was approved by the Institutional Review Board (IRB) of the study hospital (Institutional Review Board of Chang Gung Medical Foundation, approval number: 201600974B0). The need of informed consent was waived because of the lack of different intervention to patient groups and no breach of patient privacy.

With the approval of IRB, we accessed and searched the health information system (HIS) of Linkou ChangGung Memorial Hospital (CGMH) during Jan. 2002 to Dec. 2015 by using the diagnosis codes (ICD9: 36,000, $36,001,36,002,36,019)$ from the discharge summary of all admission patients. The records of 1145 consecutive patients with diagnosis codes of endophthalmitis from January 2002 to December 2015 were reviewed retrospectively. Patients with end stage renal disease (ESRD) received chronic dialysis that developed endophthalmitis were included. Patients younger than 18-year-old or those undergone solid organ or hematologic stem cell transplant were excluded. The demographic, clinical and laboratory data were collected. The patients were considered cancer/malignancy-free if no relevant information obtained from the HIS or he/she has survived more than 5 years after cancer treatment. The ongoing treatment modality for those with active cancer were also recorded. After excluding patients with abnormal renal function (serum creatinine $>1.0 \mathrm{mg} / \mathrm{dL}$ ) from the previously mentioned 1145 patients with endophthalmitis, we performed an 1:2 case-control match on propensity score dependent on age, sex and the presence of diabetes mellitus.

The visual acuity was expressed as a Snellen test measured at 6-m distance (6/6 vision). Visual acuity below 6/60 was further divided into four categories with a descending order, i.e., count fingers (CF), hand movement (HM), perception of light (PL) and no perception of light (NPL). The visual outcomes were categorized into four groups: improvement, stationary, deterioration, or enucleation. Improvement of visual acuity was defined as a gain of more than two lines of Snellen visual acuity or a one-step improvement of the "below Snellen" scales (e.g. PL to HM, or CF to 6/60). Deterioration was defined as a loss of more than two lines of Snellen visual acuity or a one-step worsening of the "below Snellen" scales (e.g. 6/60 to CF, PL to NPL, or CF to HM). Patients with endophthalmitis were further classified into endogenous or exogenous group. The exogenous group was defined as those received within 6 weeks after ophthalmologic surgery or eyeball trauma. The rest of patients were classified into endogenous group.

\section{Statistical analysis}

The categorical variables are presented with proportion and are compared by Chi-square test. The continuous variables including age, C-reactive protein and white blood count level are presented with mean and standard deviation, and these variables are tested by independent T-test. Variables such as post-operative duration and the duration between symptom onset to the day evaluated by ophthalmologist are presented as a range and median. All statistical analysis are performed by SPSS version 17 .

\section{Results}

We enrolled 1145 hospitalized patients with a discharge diagnosis coding of endophthalmitis from a total of 1,494,342 admission episodes since January 1, 2002 till December 31, 2015 (ICD9 code: 36,000, 36,001, 36,002, and 36,019$)$. A total of 41 episodes of endophthalmitis were found in patients received dialysis procedure during their hospitalization. After thorough chart review, nine episodes were excluded (one was pediatric patient, two patients had acute kidney injury, one suffered endophthalmitis before entering ESRD, one with glaucoma rather than endophthalmitis, and four with erroneous coding from previous episode). Of the 32 chronic dialysis patients entering final analysis, 25 were classified into endogenous whereas the other 7 were exogenous. The clinical information of these patients were summarized in Tables 1 and 2 for endogenous and exogenous endophthalmitis, respectively. After propensity score matching based on age, sex and DM, a total of 57 patients with normal renal function were sorted as control group, with 31 endogenous and 26 exogenous endophthalmitis. The demographic data of the dialysis and control group were summarized in Table 3.

Diabetes mellitus was the most frequent co-morbidity across all groups. Hypertension, coronary artery disease and congestive heart failure were more frequent in the dialysis, endogenous endophthalmitis group compared with control $(p<0.05)$. Only one dialysis patient in the endogenous group takes prednisolone $5 \mathrm{mg}$ per day for underlying systemic lupus erythematosus (SLE). Three dialysis patients in the endogenous and one patient in the exogenous group had active hepatocellular carcinoma (HCC), and all of them received local treatment with repetitive radiofrequency ablation or trans-arterial 
Table 1 Clinical summary of 25 chronic dialysis patients with endogenous endophthalmitis

\begin{tabular}{|c|c|c|c|c|c|c|c|c|c|c|}
\hline No. & Gender & Age & $\begin{array}{l}\text { Eyes } \\
\text { involved }\end{array}$ & $\begin{array}{l}\text { Immuno- } \\
\text { compromised } \\
\text { status }\end{array}$ & Bacteremia & Vitreous culture & $\begin{array}{l}\text { Initial visual } \\
\text { acuity }\end{array}$ & $\begin{array}{l}\text { Final visual } \\
\text { acuity }\end{array}$ & Treatment & $\begin{array}{l}\text { Concomitant } \\
\text { infection } \\
\text { focus \& signs }\end{array}$ \\
\hline 1 & $M$ & 87 & Right & $\begin{array}{l}\text { cirrhosis, } \\
\text { active HCC }\end{array}$ & & $\mathrm{Kp}$ & - & Enucleation & Enucleation & \\
\hline 2 & M & 51 & Right & & & N/A & CF & $\mathrm{CF}$ & $\begin{array}{l}\text { Parenteral } \\
\text { antifungus }\end{array}$ & \\
\hline 3 & M & 67 & Right & DM & ORSA & N/A & - & - & $\begin{array}{l}\text { Parenteral } \\
\text { antibiotics }\end{array}$ & TCC infection \\
\hline 4 & M & 53 & Both & DM & OSSA & N/A & CF & $\mathrm{CF}$ & $\begin{array}{l}\text { Parenteral } \\
\text { antibiotics }\end{array}$ & \\
\hline 5 & $F$ & 69 & Left & DM & CoNS & CoNs & - & - & IVI,TPPV & AVG infection \\
\hline 6 & $F$ & 56 & Left & & & negative & $P L$ & $P L$ & $\begin{array}{l}\text { Parenteral } \\
\text { antibiotics }\end{array}$ & \\
\hline 7 & $F$ & 84 & Right & DM & & PsA & NPL & $N P L$ & IVI & \\
\hline 8 & M & 66 & Right & DM & & negative & $N P L$ & $N P L$ & IVI & \\
\hline 9 & $\mathrm{~F}$ & 70 & Right & DM & & ORSA & $H M$ & $\mathrm{HM}$ & $\begin{array}{l}\text { Parenteral } \\
\text { antibiotics }\end{array}$ & \\
\hline 10 & M & 59 & Left & DM & & negative & CF & $\mathrm{CF}$ & $\begin{array}{l}\text { Parenteral } \\
\text { antibiotics }\end{array}$ & \\
\hline 11 & M & 60 & Left & DM & ORSA, PsA & PsA & N/A & N/A & $\begin{array}{l}\text { Parenteral } \\
\text { antibiotics }\end{array}$ & Pneumonia \\
\hline 12 & $\mathrm{~F}$ & 75 & Left & & & Kp, CoNS & $6 / 60$ & $6 / 20$ & IVI,TPPV & \\
\hline 13 & M & 61 & Left & DM & & negative & NPL & $N P L$ & IVI & \\
\hline 14 & $\mathrm{~F}$ & 86 & Right & & Bacillus cerues & negative & $N P L$ & Enucleation & Enucleation & TCC infection \\
\hline 15 & $F$ & 71 & Left & DM & & negative & N/A & Enucleation & Enucleation & \\
\hline 16 & $\mathrm{~F}$ & 70 & Right & DM & & Fungal: Acremonium & HM & CF & IVI & \\
\hline 17 & $F$ & 38 & Right & $\begin{array}{l}\text { Prednisolone } \\
5 \mathrm{mg} / \text { day }\end{array}$ & & N/A & $6 / 20$ & $6 / 20$ & $\begin{array}{l}\text { Parenteral } \\
\text { antibiotics }\end{array}$ & $\begin{array}{l}\text { PAOD with } \\
\text { gangrenes }\end{array}$ \\
\hline 18 & $\mathrm{~F}$ & 54 & Right & DM & OSSA & negative & $P L$ & $P L$ & IVI & TCC infection \\
\hline 19 & M & 62 & Left & DM & & negative & CF & $\mathrm{CF}$ & IVI & DM foot infection \\
\hline 20 & $F$ & 52 & Both & DM & & Kp & N/A & $\mathrm{CF}$ & IVI & UTI \\
\hline 21 & M & 80 & Right & DM & PsA & PsA & N/A & Enucleation & Enucleation & \\
\hline 22 & M & 66 & Left & $\begin{array}{l}\text { DM, cirrhosis, } \\
\text { active HCC }\end{array}$ & & negative & $N P L$ & $N P L$ & IVI & \\
\hline 23 & M & 46 & Right & DM & & negative & $N P L$ & $N P L$ & $\mid \mathrm{VI}$ & \\
\hline 24 & $F$ & 78 & Right & nil & & negative & NPL & Enucleation & Enucleation & \\
\hline 25 & $F$ & 49 & Right & DM & ORSA & $\begin{array}{l}\text { Staphylococcus epidermidis } \\
\text { Pseudomonas fluorescens }\end{array}$ & $6 / 21$ & $\mathrm{CF}$ & IVI & \\
\hline
\end{tabular}

DM diabetes mellitus, HCC hepatocellular carcinoma, ORSA oxacillin-resistant Staphylococcus aureus, OSSA oxacillin-susceptible Staphylococcus aureus, CoNS coagulase negative Staphylococcus, PSA Pseudomonas aeruginosa, Kp Klebsiella pneumoniae, IVI intra-vitreous injection, TPPV trans pars plana vitrectomy, TCC tunneled cuffed catheter, AVG arterio-venous graft, $P A O D$ peripheral arterial occlusive disease, UTI urinary tract infection, CF count fingers, HM hand movement, $P L$ perception of light, NPL no perception of light, N/A not assessable because of impaired consciousness, - missing data

embolization. One dialysis patient in the endogenous group had both completely treated liver and urinary tract cancer and was in disease free status. Three patients in control group had active cancer (1 with hepatocellular carcinoma, 1 with bladder urothelial carcinoma, and 1 with eyelid basal cell carcinoma).

The clinical manifestations of endophthalmitis are summarized in Table 4. The right eye was numerically more frequently involved in the dialysis group compared with control, but this difference did not reach statistical significance. Periocular swelling and ophthalmalgia were more frequently seen in the dialysis than control group, in both endogenous and exogenous endophthalmitis $(p<0.05)$. The median duration from symptom onset to the visit of ophthalmologist were 2 days in dialysis group and 3 days in control group. For endogenous endophthalmitis, the proportion of fever, shock, respiratory failure, or bacteremia were not statistically different in dialysis and 
Table 2 Clinical summary of 7 chronic dialysis patients with exogenous endophthalmitis

\begin{tabular}{|c|c|c|c|c|c|c|c|c|c|}
\hline No. & Gender & Age & Eyes involved & $\begin{array}{l}\text { Immunocompromised } \\
\text { status }\end{array}$ & Vitreous culture & Surgery before infection & $\begin{array}{l}\text { Initial visual } \\
\text { acuity }\end{array}$ & $\begin{array}{l}\text { Final visual } \\
\text { acuity }\end{array}$ & Treatment \\
\hline 1 & M & 47 & Right & $\mathrm{DM}$ & Negative & Cataract surgery & - & - & $\begin{array}{l}\text { Parenteral } \\
\text { antibiotics }\end{array}$ \\
\hline 2 & M & 60 & Left & DM & ORSA & Cataract surgery & - & - & IVI,TPPV \\
\hline 3 & $\mathrm{~F}$ & 67 & Right & Nil & NFGNB & Cataract surgery & $6 / 30$ & $6 / 30$ & IVI \\
\hline 4 & M & 56 & Right & $\mathrm{DM}$ & Enterococcus faecalis & Cataract surgery & PL & CF & IVI \\
\hline 5 & M & 64 & Left & $\mathrm{DM}$ & $\begin{array}{l}\text { Stenotrophomonas } \\
\text { maltopilia }\end{array}$ & Cataract surgery & CF & $6 / 15$ & IVI \\
\hline 6 & M & 73 & Right & DM & negative & Cataract surgery & CF & CF & IVI,TPPV \\
\hline 7 & M & 66 & Left & $\begin{array}{l}\text { DM, cirrhosis, } \\
\text { active HCC }\end{array}$ & Enterococcus faecalis & $\begin{array}{l}\text { TPPV with endo-laser for } \\
\text { vitreous hemorrhage }\end{array}$ & $\mathrm{HM}$ & NPL & IVI,TPPV \\
\hline
\end{tabular}

DM diabetes mellitus, HCC hepatocellular carcinoma, ORSA oxacillin-resistant Staphylococcus aureus, NFGNB glucose non-fermenting Gram negative bacilli, IVI intra-vitreous injection, TPPV trans pars plana vitrectomy, PL perception of light, NPL no perception of light, - missing data

control group. The initial WBC were numerically higher in the endogenous than exogenous endophthalmitis but did not reach statistical significance. The CRP level were significantly higher in the endogenous than exogenous endophthalmitis in the control group $(p<0.05)$ but not in the dialysis group $(p=0.065)$. In dialysis patients with endogenous endophthalmitis, three patients with tunneled cuffed catheter (TCC) and one patient with arterio-venous graft (AVG) had evidences of dialysis vascular access infection at the presentation of endophthalmitis. Eight patients in the endogenous group received only parenteral antibiotic treatment because of various reasons including less severe intraocular involvement, patient refusal, or contraindication such as severe thrombocytopenia.

The outcomes regarding visual acuity were summarized in Table 5 . There were missing data of 5 patients in the earliest era (2002-2003). Another two patients in the endogenous group were unable to evaluate visual acuity because of impaired consciousness at presentation. After treatment, visual acuity of most patients in both group remained stationary, while only a small fraction of them achieve some degree of improvement. Most

Table 3 Demographic data of chronic dialysis patients versus patients with normal renal function

\begin{tabular}{|c|c|c|c|c|c|c|c|c|}
\hline \multirow[b]{3}{*}{ Male } & \multicolumn{4}{|l|}{ Dialysis } & \multicolumn{4}{|c|}{ Control } \\
\hline & \multicolumn{2}{|c|}{ Endogenous $(N=25)$} & \multicolumn{2}{|c|}{ Exogenous $(N=7)$} & \multicolumn{2}{|c|}{ Endogenous $(N=31)$} & \multicolumn{2}{|c|}{ Exogenous $(N=26)$} \\
\hline & 12 & $48.0 \%$ & 6 & $85.7 \%$ & 16 & $51.6 \%$ & 13 & $50.0 \%$ \\
\hline Age & 64 & \pm 13 & 62 & \pm 8 & 61 & \pm 12 & 67 & \pm 13 \\
\hline \multicolumn{9}{|l|}{ Co-morbidities } \\
\hline Diabetes mellitus & 18 & $72.0 \%$ & 6 & $85.7 \%$ & 24 & $77.4 \%$ & 14 & $53.8 \%$ \\
\hline Hypertension & 20 & $80.0 \%^{\#}$ & 5 & $71.4 \%$ & 13 & $41.9 \%$ & 10 & $38.5 \%$ \\
\hline Coronary artery disease & 7 & $28.0 \%^{\#}$ & 1 & $14.3 \%$ & 1 & $3.2 \%$ & 0 & $0 \%$ \\
\hline Congestive heart failure & 6 & $24.0 \%{ }^{\#}$ & 1 & $14.3 \%$ & 0 & $0 \%$ & 0 & $0 \%$ \\
\hline Stroke & 4 & $16.0 \%$ & 2 & $28.6 \% *$ & 1 & $3.2 \%$ & 0 & $0 \%$ \\
\hline Hepatitis B & 1 & $4.0 \%$ & 0 & $0 \%$ & 2 & $6.5 \%$ & 1 & $3.8 \%$ \\
\hline Hepatitis C & 3 & $12.0 \%$ & 2 & $28.6 \% *$ & 2 & $6.5 \%$ & 0 & $0 \%$ \\
\hline Cirrhosis & 2 & $8.0 \%$ & 1 & $14.3 \%$ & 4 & $12.9 \%$ & 0 & $0 \%$ \\
\hline Cancer & 3 & $12.0 \%$ & 1 & $14.3 \%$ & 3 & $9.7 \%$ & 0 & $0 \%$ \\
\hline Immunosuppression & 1 & $4.0 \%$ & 0 & $0 \%$ & 0 & $0 \%$ & 0 & $0 \%$ \\
\hline Vascular access & $\mathrm{HD}=24^{+}, \mathrm{PD}=1$ & $\mathrm{HD}=7$ & & & & & & \\
\hline AVF & 15 & $62.5 \%$ & 7 & $100 \%$ & & & & \\
\hline AVG & 1 & $4.1 \%$ & 0 & & & & & \\
\hline TCC & 9 & $37.5 \%$ & 0 & & & & & \\
\hline
\end{tabular}

AVF native arterio-venous fistula, $A V G$ arterio-venous graft, $T C C$ tunneled cuffed catheter, $H D$ hemodialysis, $P D$ peritoneal dialysis

${ }^{+}$One hemodialysis patient in the endogenous group had both AVF and TCC

$\# p<0.05$ Endogenous: Dialysis v.s. Control

${ }^{*} p<0.05$ Exogenous: Dialysis v.s. Control 
Table 4 Clinical presentations and treatments for chronic dialysis patients versus patients with normal renal function

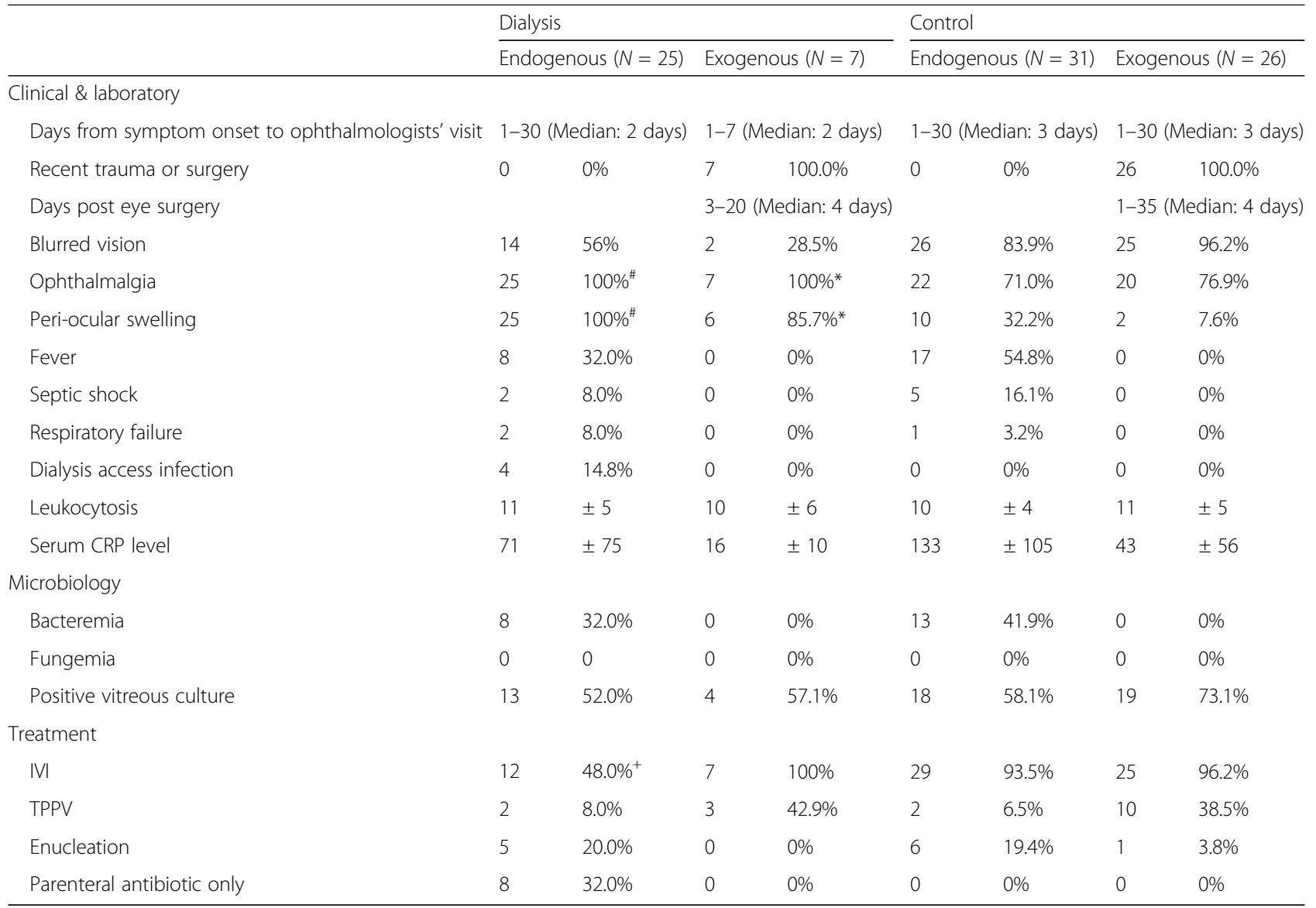

CRP C-Reactive protein, IVI intra-vitreous injection, TPPV trans pars plana vitrectomy

$\# p<0.05$ Endogenous: Dialysis v.s. Control

${ }^{*} p<0.05$ Exogenous: Dialysis v.s. Control

${ }^{+} p<0.05$ Endogenous: Dialysis v.s. Control

Table 5 Visual acuity before and after treatment for chronic dialysis patients versus patients with normal renal function

\begin{tabular}{|c|c|c|c|c|c|c|c|c|}
\hline \multirow{2}{*}{ Initial visual acuity } & \multicolumn{4}{|c|}{ Dialysis } & \multicolumn{4}{|c|}{ Control } \\
\hline & \multicolumn{2}{|c|}{ Endogenous $(N=25)$} & \multicolumn{2}{|c|}{ Exogenous $(N=7)$} & \multicolumn{2}{|c|}{ Endogenous $(N=31)$} & \multicolumn{2}{|c|}{ Exogenous $(N=26)$} \\
\hline Below 6/60 & 15 & $60.0 \%$ & 4 & $57.1 \%$ & 25 & $80.1 \%$ & 22 & $84.6 \%$ \\
\hline Better or equal to $6 / 60$ & 3 & $12.0 \%$ & 1 & $14.3 \%$ & 6 & $19.9 \%$ & 4 & $15.4 \%$ \\
\hline Unable to assess/data missing & 7 & $28.0 \%$ & 2 & $28.6 \%$ & 0 & $0 \%$ & 0 & $0 \%$ \\
\hline \multicolumn{9}{|l|}{ Follow up visual acuity } \\
\hline Below 6/60 & 19 & $76.0 \%$ & 3 & $42.8 \%$ & 24 & $77.4 \%$ & 12 & $46.1 \%$ \\
\hline Better or equal to $6 / 60$ & 2 & $8.0 \%$ & 2 & $28.6 \%$ & 7 & $22.6 \%$ & 14 & $53.9 \%$ \\
\hline Unable to assess/data missing & 4 & $16.0 \%$ & 2 & $28.6 \%$ & 0 & $0 \%$ & 0 & $0 \%$ \\
\hline \multicolumn{9}{|l|}{ Outcome by visual acuity } \\
\hline Improvement & 1 & $4.0 \%$ & 1 & $14.3 \%$ & 9 & $29.0 \%{ }^{\#}$ & 15 & $57.7 \%^{*}$ \\
\hline Stable & 11 & $44.0 \%$ & 3 & $42.8 \%$ & 9 & $29.0 \%$ & 7 & $26.9 \%$ \\
\hline Deterioration & 4 & $16.0 \%$ & 1 & $14.3 \%$ & 5 & $16.1 \%$ & 2 & $7.7 \%$ \\
\hline Enucleation & 4 & $16.0 \%$ & 0 & $0 \%$ & 6 & $19.4 \%$ & 2 & $7.7 \%$ \\
\hline Unable to assess/data missing & 5 & $20.0 \%$ & 2 & $28.6 \%$ & 2 & $6.5 \%$ & 0 & $0 \%$ \\
\hline
\end{tabular}


of patients in endogenous group had final visual acuity below $6 / 60$ (76\%), while $42.8 \%$ of patients in exogenous group had final visual acuity below 6/60. Comparison of the proportion of visual acuity better than $6 / 60$ on the Snellen scale at initial or follow up evaluation did not show significant differences between dialysis and control group. However, more patients with endogenous endophthalmitis in control group achieved improvement of visual acuity than the dialysis group $(p=0.012)$. The odds ratio (OR) of no improvement in visual acuity of the dialysis group compared to the control is 9.8 (95\% confidence interval: $1.1-83.9, p=0.037$ ). The outcome of exogenous endophthalmitis was better than endogenous in the control group $(p=0.015)$.

The blood and vitreous cultures were listed in Table 6 . In the endogenous group, only three patients had positive blood and vitreous culture with same microorganisms. Staphylococcus species, Klebsiella pneumoniae and Pseudomonas species are among the most common isolated pathogens of endogenous endophthalmitis in the dialysis group. In control group, Klebsiella pneumoniae was the most common pathogen identified in those with endogenous endophthalmitis, and most of these patients suffered Klebsiella pneumoniae

Table 6 Microbiological features of endophthalmitis in chronic dialysis patients

\begin{tabular}{|c|c|c|c|c|c|c|c|c|}
\hline & \multicolumn{4}{|c|}{ Dialysis } & \multicolumn{4}{|c|}{ Control } \\
\hline & \multicolumn{3}{|c|}{ Endogenous $(N=25)$} & \multirow{2}{*}{$\begin{array}{l}\text { Exogenous }(N=7) \\
\text { Vitreous }\end{array}$} & \multicolumn{3}{|c|}{ Endogenous $(N=31)$} & \multirow{2}{*}{$\begin{array}{l}\text { Exogenous }(N=26) \\
\text { Vitreous }\end{array}$} \\
\hline & $\begin{array}{l}\text { Blood } \\
\text { only }\end{array}$ & $\begin{array}{l}\text { Vitreous } \\
\text { only }\end{array}$ & $\begin{array}{l}\text { Blood + } \\
\text { Vitreous }\end{array}$ & & $\begin{array}{l}\text { Blood } \\
\text { only }\end{array}$ & $\begin{array}{l}\text { Vitreous } \\
\text { only }\end{array}$ & $\begin{array}{l}\text { Blood + } \\
\text { Vitreous }\end{array}$ & \\
\hline \multicolumn{9}{|l|}{ Gram positive bacteria } \\
\hline ORSA & 4 & 1 & & 1 & 1 & & & \\
\hline OSSA & 1 & & & & 1 & 1 & & \\
\hline CONS & & 2 & 1 & & & 1 & & 6 \\
\hline Staphylococcus epidermidis & & & & & & & & 1 \\
\hline Staphylococcous homonis & & & & & & & & 1 \\
\hline Streptococcus pneumoniae & & & & & & 2 & & \\
\hline Group B Streoptococcus & & & & & 2 & & & \\
\hline Streptococcus oralis & & & & & & & & 1 \\
\hline Enterococcus faecalis & & 1 & & 1 & 1 & & & 3 \\
\hline Aerococcus & & & & & & 1 & & \\
\hline Bacillus cerues & 1 & & & & & & & \\
\hline \multicolumn{9}{|l|}{ Gram negative bacteria } \\
\hline Klebsiella pneumoniae & & 3 & & & & 3 & 4 & \\
\hline Pseudomonas aeruginosa & & 1 & 2 & & & & & 2 \\
\hline Pseudomonas fluorescens & & 1 & & & & & & \\
\hline Morganella morganii & & & & & & & & 1 \\
\hline Stenotrophomonas maltophilia & & & & 1 & & & & 2 \\
\hline$N F G N B$ & & & & 1 & & & & \\
\hline Myroides odoratus & & & & & & & & 1 \\
\hline Ochrobacterium sp. & 1 & & & & & & & \\
\hline \multicolumn{9}{|l|}{ Fungi } \\
\hline Acremonium & & 1 & & & & & & \\
\hline Aureobasidium & & & & & & & & 1 \\
\hline Candida parasilosis & & & & & & 1 & & 1 \\
\hline Fusarium & & & & & & & & 1 \\
\hline Pseudoallescheria boydii & & & & & & 1 & & \\
\hline Scopulariosis & & & & & & & & 1 \\
\hline Trichosporon & & & & & & & & 1 \\
\hline
\end{tabular}


bacteremia from various focus including hepatic, renal and retroperitoneal abscesses; while Coagulase-negative Staphylococcus and Enterococcus faecalis were the most common pathogen causing exogenous endophthalmitis in the control group.

\section{Discussion}

Endophthalmitis is a serious condition that may leads to blindness, for which prompt management may be associated with the vision outcome $[1,2]$. It can be generally divided into endogenous or exogenous. The exogenous endophthalmitis is more common, and can be resulted from surgery, trauma or extension of ocular surface infection. The endogenous endophthalmitis is rare, accounting for only $5-10 \%$ of the endophthalmitis population, and is mostly caused by secondary inoculation of microorganisms from infective foci such as wound, endocarditis, liver abscess, and urinary tract infection, etc. $[1,2,7]$. In our case series, the prevalence of endogenous endophthalmitis is higher than exogenous endophthalmitis in chronic dialysis patients.

Chronic dialysis patients have defects in both innate and adaptive immunity, thus predispose them to infectious disease $[12,13]$. However, only a few case reports described endogenous endophthalmitis of dialysis patients in the literature. These case reports highlight that vascular access should be considered as a possible and unique infection source in dialysis population [15-18]. In a retrospective study in Denmark, the incidence of first episode of bloodstream infection in dialysis patients is higher than that in population control [19]. This group also demonstrated a very high incidence of Staphylococcal bacteremia in dialysis patient [20]. Studies from Canada also found that dialysis is a strong risk factors of both Pseudomonal and anaerobic bacteremia $[21,22]$. Because of the higher incidence of bloodstream infection, the dissemination of bacteria into various organs becomes an important issue. In studies focusing on general population with endophthalmitis, the most common pathogens are Staphylococcus aureus [3, 5, 6, 8, 23], Klebsiella pneumonia [3, 6, 7], and Candida species [5-7]. In our case series, the main bacteria isolates from dialysis population include Staphylococcus species, Klebsiella pneumonia, and Pseudomonas aeruginosa; while in the control group, the most common pathogens include Klebsiella pneumonia, Staphylococcus species, and Enterococcus faecalis. The most prominent difference is the presence of Pseudomonas aeruginosa and this implies the necessity of anti-pseudomonal coverage in empiric treatment for endogenous endophthalmitis in chronic dialysis patients.

Chronic dialysis patients are also frequently subjected to bacteremia because of vascular access infection [24]. In our study, 4 of the 25 patients diagnosed with endogenous endophthalmitis have documented vascular access infection. All of them have arterio-venous grafts or tunneled cuffed catheter, which is compatible with previous studies indicating higher risk of bloodstream infection when using vascular access other than native arterio-venous fistula [25, 26]. However, because of the lack of concordance in blood and vitreous culture in three of four dialysis patients, we cannot conclude the causal relationship between the vascular access infection and endogenous endophthalmitis, but only address the possibility of unique bacterial source in the dialysis group.

The outcome of endogenous endophthalmitis is poor but with some improvement over the last two to three decades $[3,4]$. Compared with more recent endogenous endophthalmitis in general population and our control group, the dialysis patients may have poorer initial visual acuity and less favorable visual outcomes $[5,6,8]$. This may be explained by higher proportion of diabetes mellitus (72\%) in our group than in studies of general populations $(29 \sim 62 \%)[3-8,23]$. The higher proportion of diabetes mellitus in out chronic dialysis patients can explain more prevalent diabetic retinopathies before the index episode of endophthalmitis. The initial visual acuity is associated with final visual outcome, as shown in a retrospective study by Nishida et al. [8]. Any delay in diagnosis will possibly lead to worse visual outcome $[3,4,23]$.

We found 7 dialysis patient had exogenous endophthalmitis after surgery. Six patients are male and six patients have diabetes mellitus (DM). Male gender and DM have been described as patient-associated pre-operative risk factors for post cataract surgery endophthalmitis [11]. Based on previous studies and meta-analysis, prophylaxis with intracameral injection of cefuroxime reduce the rate of post cataract surgery endophthalmitis [27-29]. Because our patients underwent cataract surgery in other ophthalmologic clinic, we were not aware of the use of prophylaxis antibiotic during the surgery. The visual outcome of exogenous group is better than endogenous group in our patient series (proportion of final visual acuity better than $6 / 60: 28.6 \%$ v.s. $8.0 \%$ ). Although more patients in the control group achieve visual acuity better than 6/60, the difference is not statistically significant (control: $53.9 \%$ v.s. dialysis: $28.6 \%, p=0.235$ ). By comparing the proportion of final visual acuity better than $6 / 60$, the dialysis group with exogenous endophthalmitis has worse outcome than that in the general population. Choi et al. reviewed the outcome of post-cataract surgery endophthalmitis in Asia and found the final visual acuity better than 20/200 were between 31.6 to $100 \%$ [30]. In a nationwide 6-year cohort in Sweden, Friling et al. reported the proportion of final visual outcome better than $20 / 200$ to be $66.6 \%$ [31]. 


\section{Conclusion}

To our knowledge, this is the largest series of endophthalmitis in chronic dialysis patients and provides important information to the nephrologists. Firstly, as compared with general population, the prevalence of endogenous endophthalmitis is higher than exogenous endophthalmitis in chronic dialysis patients. Second, Staphylococcus species, Klebsiella pneumoniae and Pseudomonas species are among the most common isolated pathogens of endogenous endophthalmitis. Also, the vascular access should be closely evaluated because it may be a possible focus of bacterial entry in chronic dialysis patients. Third, the visual outcomes of endophthalmitis in dialysis patient may be worse than general population. Because of the potentially dismal outcome, high alert of eye symptoms in chronic dialysis patients and prompt referral to ophthalmologists are suggested for the salvage of visual acuity.

The limitation of our study includes small case numbers that may lead to inadequate power to detect smaller differences between the variables. The retrospective chart review provide evidences of association, but may not imply causal relationship.

\begin{abstract}
Abbreviations
AVF: Native arterio-venous fistula; AVG: Arterio-venous graft; CF: Count fingers; CoNS: Coagulase negative Staphylococcus; CRP: C-reactive protein; DM: Diabetes mellitus; ESRD: End stage renal disease; HCC: Hepatocellular carcinoma; HD: Hemodialysis; HM: Hand movement; IVI: Intra-vitreous injection; Kp: Klebsiella pneumoniae; NFGNB: Glucose non-fermenting Gram negative bacilli; NPL: No perception of light; ORSA: Oxacillin-resistant Staphylococcus aureus; OSSA: Oxacillin-susceptible Staphylococcus aureus; PAOD: Peripheral arterial occlusive disease; PD: Peritoneal dialysis; PL: Perception of light; PsA: Pseudomonas aeruginosa; SLE: Systemic lupus erythematosus; TCC: Tunneled cuffed catheter; TPPV: Trans pars plana vitrectomy; UTI: Urinary tract infection
\end{abstract}

\section{Acknowledgements}

The authors would like to thank Research Grant from Linkou Chang-Gung Memorial Hospital (Grant CMRPG300223) and Taiwan Ministry of Science \& Technology (Grant NMRPG3E0611) for the support of the maintenance project.

\section{Funding}

The corresponding author received research funding from Linkou Chang-Gung Memorial Hospital (Grant CMRPG3E1292) and Taiwan Ministry of Science \& Technology (Grant NMRPG3E0611).

\section{Availability of data and materials}

The data that support the findings of this study are available from the corresponding author upon reasonable request.

\section{Authors' contributions}

GK and YAL wrote the article; GK did the major works for manuscript revision; WCS, CYC and CHL executed clinical data collection; HKK conducted the literature search; YJL, CCH and YCT performed data analysis, statistics and discussion; $\mathrm{HHH}$ conceived the idea behind the manuscript, oversaw and contributed to the writing of the manuscript and serves as the guarantor. All authors read and approved the final manuscript.

\section{Ethics approval and consent to participate}

This study protocol was approved by the Institutional Review Board (IRB) of the study hospital (Institutional Review Board of Chang Gung Medical Foundation, approval number: 201600974B0). The need of informed consent was waived because of the lack of different intervention to patient groups and no breach of patient privacy.
Consent for publication

Not applicable.

\section{Competing interests}

The authors declare that they have no competing interests.

\section{Publisher's Note}

Springer Nature remains neutral with regard to jurisdictional claims in published maps and institutional affiliations.

\section{Author details}

'Department of Nephrology, Kidney Research Center, Linkou Chang Gung Memorial Hospital, Chang Gung University, College of Medicine, No.5 Fu-Shin Street, Kwei-shan, Taoyuan 333, Taiwan. ${ }^{2}$ Department of Plastic and Reconstructive Surgery, Linkou Chang Gung Memorial Hospital, Chang Gung University, College of Medicine, Taoyuan, Taiwan. ${ }^{3}$ Center for Big Data Analytics and Statistics, Linkou Chang Gung Memorial Hospital, Chang Gung University, College of Medicine, Taoyuan, Taiwan. ${ }^{4}$ Department of Pharmaceutical Materials Management, Taoyuan Chang Gung Memorial Hospital, Taoyuan, Taiwan.

Received: 13 May 2017 Accepted: 5 August 2017

Published online: 16 August 2017

References

1. Cunningham C, Raiji V. Endophthalmitis. Dis Mon. 2017;63(2): 45-48.

2. Schwartz SG, Flynn HWJ, Das T, Mieler WF. Ocular infection: Endophthalmitis. Dev Ophthalmol. 2016:55:176-88.

3. Jackson TL, Paraskevopoulos T, Georgalas I. Systematic review of 342 cases of endogenous bacterial endophthalmitis. Surv Ophthalmol. 2014;59:627-35.

4. Jackson TL, Eykyn SJ, Graham EM, Stanford MR. Endogenous bacterial endophthalmitis: a 17-year prospective series and review of 267 reported cases. Surv Ophthalmol. 2003;48:403-23.

5. Zhang H, Liu Z. Endogenous endophthalmitis: a 10-year review of culturepositive cases in northern China. Ocul Immunol Inflamm. 2010;18:133-8.

6. Connell PP, O'Neill EC, Fabinyi D, et al. Endogenous endophthalmitis: 10-year experience at a tertiary referral centre. Eye (Lond). 2011;25:66-72.

7. Wu ZH, Chan RP, Luk FO, et al. Review of clinical features, microbiological Spectrum, and treatment outcomes of endogenous Endophthalmitis over an 8-year period. J Ophthalmol. 2012;2012:265078.

8. Nishida T, Ishida K, Niwa Y, Kawakami H, Mochizuki K, Ohkusu K. An eleven-year retrospective study of endogenous bacterial endophthalmitis. J Ophthalmol. 2015;2015:261310.

9. Cao H, Zhang L, Li L, Lo S. Risk factors for acute endophthalmitis following cataract surgery: a systematic review and meta-analysis. PLoS One. 2013;8:e71731.

10. Hatch WV, Cernat G, Wong D, Devenyi R, Bell CM. Risk factors for acute endophthalmitis after cataract surgery: a population-based study. Ophthalmology. 2009;116:425-30.

11. Hashemian H, Mirshahi R, Khodaparast M, Jabbarvand M. Post-cataract surgery endophthalmitis: brief literature review. J Curr Ophthalmol. 2016;28:101-5.

12. Kato $\mathrm{S}$, Chmielewski $\mathrm{M}$, Honda $\mathrm{H}$, et al. Aspects of immune dysfunction in end-stage renal disease. Clin J Am Soc Nephrol. 2008;3:1526-33.

13. Eleftheriadis T, Antoniadi G, Liakopoulos V, Kartsios C, Stefanidis I. Disturbances of acquired immunity in hemodialysis patients. Semin Dial. 2007:20:440-51.

14. Berman SJ, Johnson EW, Nakatsu C, Alkan M, Chen R, LeDuc J. Burden of infection in patients with end-stage renal disease requiring long-term dialysis. Clin Infect Dis. 2005;39:1747-53.

15. Aggarwal M, Vijan V, Vupputuri A, Nandakumar S, Mathew N. A rare case of fatal Endocarditis and sepsis caused by Pseudomonas aeruginosa in a patient with chronic renal failure. J Clin Diagn Res. 2016;10:OD12-3.

16. Saleem MR, Mustafa S, Drew PJ, et al. Endophthalmitis, a rare metastatic bacterial complication of haemodialysis catheter-related sepsis. Nephrol Dial Transplant. 2007;22:939-41.

17. Cabana-Carcasi ML, Becerra-Mosquera V, Gonzalez-Tabares L, Novoa-Garcia D. Endogenous endophthalmitis as a complication of sepsis related to a tunnelled haemodialysis catheter. Nefrologia. 2012;32:255-6. 
18. de Lima LM, Cecchetti SA, Cecchetti DF, et al. Endophthalmitis: a rare but devastating metastatic bacterial complication of hemodialysis catheter-related sepsis. Ren Fail. 2012;34:119-22.

19. Skov Dalgaard L, Norgaard M, Jespersen B, et al. Risk and prognosis of bloodstream infections among patients on chronic Hemodialysis: a population-based cohort study. PLoS One. 2015;10:e0124547.

20. Nielsen LH, Jensen-Fangel S, Benfield T, et al. Risk and prognosis of Staphylococcus Aureus bacteremia among individuals with and without end-stage renal disease: a Danish, population-based cohort study. BMC Infect Dis. 2015;15:6.

21. Parkins MD, Gregson DB, Pitout JD, Ross T, Laupland KB. Population-based study of the epidemiology and the risk factors for Pseudomonas Aeruginosa bloodstream infection. Infection. 2010;38:25-32.

22. Ngo JT, Parkins MD, Gregson DB, et al. Population-based assessment of the incidence, risk factors, and outcomes of anaerobic bloodstream infections. Infection. 2013;41:41-8.

23. Okada AA, Johnson RP, Liles WC, D'Amico DJ, Baker AS. Endogenous bacterial endophthalmitis. Report of a ten-year retrospective study. Ophthalmology. 1994;101:832-8.

24. Wang IK, Chang Y-C, Liang C-C, et al. Bacteremia in Hemodialysis and peritoneal dialysis patients. Intern Med. 2012;51:1015-21.

25. Stevenson KB, Hannah EL, Lowder CA, et al. Epidemiology of hemodialysis vascular access infections from longitudinal infection surveillance data: predicting the impact of NKF-DOQI clinical practice guidelines for vascular access. Am J Kidney Dis. 2002;39:549-55.

26. Taylor G, Gravel D, Johnston L, et al. Incidence of bloodstream infection in multicenter inception cohorts of hemodialysis patients. Am J Infect Control. 2004;32:155-60

27. Seal DV, Barry P, Gettinby G, et al. ESCRS study of prophylaxis of postoperative endophthalmitis after cataract surgery: case for a European multicenter study. J Cataract Refract Surg. 2006;32:396-406.

28. Barry P, Seal DV, Gettinby G, et al. ESCRS study of prophylaxis of postoperative endophthalmitis after cataract surgery: preliminary report of principal results from a European multicenter study. J Cataract Refract Surg. 2006;32:407-10.

29. Gower EW, Lindsley K, Tulenko SE, Nanji AA, Leyngold I, McDonnell PJ. Perioperative antibiotics for prevention of acute endophthalmitis after cataract surgery. Cochrane Database Syst Rev. 2017;2:CD006364.

30. Choi JA, Chung SK. Postoperative Endophthalmitis following cataract surgery in Asia. ISRN Ophthalmol. 2011;2011:1-5.

31. Friling E, Lundstrom M, Stenevi U, Montan P. Six-year incidence of endophthalmitis after cataract surgery: Swedish national study. J Cataract Refract Surg. 2013;39:15-21.

\section{Submit your next manuscript to BioMed Central and we will help you at every step:}

- We accept pre-submission inquiries

- Our selector tool helps you to find the most relevant journal

- We provide round the clock customer support

- Convenient online submission

- Thorough peer review

- Inclusion in PubMed and all major indexing services

- Maximum visibility for your research

Submit your manuscript at www.biomedcentral.com/submit

) Biomed Central 